\title{
microRNA-150 inhibits human CD133-positive liver cancer stem cells through negative regulation of the transcription factor $\mathrm{c}-\mathrm{Myb}$
}

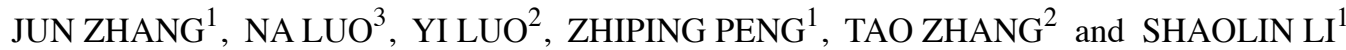 \\ ${ }^{1}$ Department of Radiology, Chongqing Medical University; ${ }^{2}$ Department of Oncology, the First Affiliated \\ Hospital of Chongqing Medical University; ${ }^{3}$ Department of Gastroenterology, the Second Affiliated \\ Hospital of Chongqing Medical University, Chongqing, P.R. China
}

Received August 28, 2011; Accepted October 12, 2011

DOI: $10.3892 /$ ijo.2011.1242

\begin{abstract}
MicroRNAs (miRNAs) have been implicated in the maintenance of the cancer stem cell (CSC) phenotype via their ability to affect expression of genes and proteins that regulate cell proliferation and/or cell death. Thus, identification of CSC-related miRNAs would provide information for a better understanding of CSCs. Here, we compared the miRNA profiles of $\mathrm{CD}_{133^{+}}$and $\mathrm{CD} 133^{-}$primary hepatocellular carcinoma (HCC) subpopulations and found upregulation of 5 miRNAs in CD133- subpopulations, including hsa-miR-150, which may be involved in maintenance of the CD133+ liver CSC phenotype. We also show that miR-150 interacts with the 3'UTR of c-Myb mRNA and overexpression of miR-150 downregulates c-Myb protein levels. Furthermore, overexpression of miR-150 lead to a significant reduction of $\mathrm{CD}_{133^{+}}$cells, accompanied by significant inhibition of cell growth and tumorsphere formation. In addition, overexpression of miR-150 induces cell cycle arrest and apoptosis in $\mathrm{CD}_{133}{ }^{+}$cells. Consistent with the outcome of cell cycle arrest and cell apoptosis, Western blotting results demonstrate that the cell cycle regulator cyclin D1 and cell survival regulator Bcl-2 are decreased in cells transfected with miR-150. Collectively, our findings demonstrate for the first time that miR-150 may be involved in liver CSC self-renewal, potentially via modulation of the downstream target c-Myb.
\end{abstract}

\section{Introduction}

The cancer stem cells (CSCs) hypothesis suggests that only a small subset of cells possesses the stem property of self-renewal,

\footnotetext{
Correspondence to: Dr Shaolin Li, Department of Radiology, Chongqing Medical University, 1 Yixueyuan Road, Chongqing 400016, P.R. China

E-mail: lishaolin@cqmu.edu.cn

Dr Tao Zhang, Department of Oncology, the First Affiliated Hospital of Chongqing Medical University, 1 Youyi Road, Chongqing 400016, P.R. China

E-mail: tumorzzt@163.com
}

Key words: microRNA, microRNA-150, cancer stem cells, c-Myb clonogenicity and tumorigenicity (1). There is accumulating evidence for CSCs in many solid tumors, including brain, breast, osteosarcoma, liver, and colon (2-7). In this study, we focused on hepatocellular carcinoma (HCC), one of most prevalent cancers in Asia and Africa. Recently, CD133 was used as a marker to isolate liver CSCs $(8,9)$.

microRNAs (miRNAs) are a novel class of small noncoding RNAs that negatively regulate gene expression (10-14). Emerging evidence suggests that miRNAs may play important roles in cancer (15-17). miRNAs can function as both oncogenes and tumor suppressors in their effect on tumor growth $(18,19)$. Recent data demonstrate that miRNAs are important factors in stem cell biology and in the determination of cell fate (20-22) whereas the knowledge on miRNAs expression in liver CSCs is still preliminary.

$\mathrm{CD} 33^{+} \mathrm{HCC}$ subpopulations with stem cell properties have been reported whereas the CD133 subpopulations include differentiated tumor cells. We hypothesize that up-regulation of miRNAs in CD133- cells indicates that they drive CD133+ cells to differentiate and lose their stem cell properties. Hence, overexpression of these miRNAs in $\mathrm{CD}_{133^{+}}$cells may inhibit cell self-renewal. Therefore, we compared the miRNA profiles of CSCs with that of the non-stem cell population in HCC. Interestingly, several miRNAs have been found up-regulated in the CD133- subpopulations. Among these miRNAs, miR-150, a gene is on chromosome 19q13, was noted during the experiments. Previous studies reported potential growthand differentiation-dependent regulatory roles for miR-150 in immune cells (23). The report from Cheng et al, indicated that ectopic expression of miR-150 induces cell cycle arrest, which is consistent with the ability of miR-150 to down-regulate a program of genes promoting cell cycle progression (24). Taken together, these studies suggest that miR-150 may have a key role in regulating the balance among cell differentiation and survival.

However, little is known about the functions of miR-150 in liver cancer stem cells. In the present study, we examined the effects of functional overexpression of miR-150 by miR-150 lentiviral vector on CD133+ SMMC-7721 cells. Evaluating the role of miR-150 in regulation of cell growth and apoptosis, and its potential link to liver cancer stem cells may provide a new avenues for therapeutic interventions for targeting liver CSCs. 


\section{Materials and methods}

HCC cell lines, HCC samples and cell culture. Human HCC cell lines (SMMC-7721, Huh-7, and Hep3B) were obtained from the Cell Bank of Institute of Biochemistry and Cell Biology, China Academy of Sciences (Shanghai, China). Tumor samples were obtained with informed consent from 5 patients who underwent hepatocellular carcinoma in the Department of Surgery, the First Affilicated Hospital, Chongqing Medical University (Chongqing, China). Tumor processing and cell cultures were done as described (9). All human sample collection procedures were approved by the China Ethics Review Committee. The characteristics of HCC patents included in this study are described in Table I.

Magnetic sorting and culture of $\mathrm{CD} 133^{+}$SMMC-7721 cells. For magnetic cell sorting cells were labeled with CD133/1 magnetic microbeads and sorted using the CD133 Cell Isolation Kit (Miltenyi Biotec), according to the manufacturer's protocol as described (8). Magnetic separation was performed to obtain $>95 \%$ pure $\mathrm{CD} 133^{+}$SMMC-7721 cells and $>95 \%$ pure $\mathrm{CD} 133$ SMMC-7721 cells. The purity of sorted cells was evaluated by FACS with the FACSCalibur apparatus (Becton-Dickinson, USA) and Western blotting.

After sorting, the $\mathrm{CD} 133^{+}$cells were cultured in serumfree stem cell medium containing DMEM/F12, $20 \mathrm{ng} / \mathrm{ml}$ basic fibroblast growth factor (bFGF, Miltenyi Biotec), $20 \mathrm{ng} / \mathrm{ml}$ epidermal growth factor (EGF, Miltenyi Biotec), $20 \mathrm{ng} / \mathrm{ml}$ leukemia inhibitory factor (LIF, Miltenyi Biotec), $100 \mathrm{IU} / \mathrm{ml}$ penicillin $\mathrm{G}$ and $100 \mu \mathrm{g} / \mathrm{ml}$ streptomycin (Sigma, USA).

Expression profiling of miRNAs. For miRNA profiles analysis, total RNA was isolated from the $\mathrm{HCC} \mathrm{CD133^{+ }}$ fractions and CD133- fractions using TRIzol (Invitrogen) and RNeasy mini kit (Qiagen), according to the instructions. Following RNA measurement on the Nanodrop instrument, the samples were labeled using the miRCURY ${ }^{\mathrm{TM}} \mathrm{Hy} 3^{\mathrm{TM}} / \mathrm{Hy}^{\mathrm{TM}}$ Power labeling kit and hybridized on the miRCURY ${ }^{\mathrm{TM}}$ locked nucleic acid (LNA) microarray platform (Exipon, Denmark). The samples were hybridized on a hybridization station. Arrays were scanned using the Axon GenePix 4000B microarray scanner. Differentially expressed miRNAs were identified using a filter based on 1.5 -fold changes combined with $\mathrm{t}$-test $(\mathrm{P}<0.01)$ for $\mathrm{CD} 133^{+}$versus $\mathrm{CD} 133$ comparisons.

Transfection of CD133+ SMMC-7721 cells. The HIV lentiviral system expression miR-150 and miR-control were commercially synthesized (Shanghai Sunbio Medical Biotechnology Co. Ltd, China). Transfection was performed with polybrene (Sigma, USA) according to the instructions. Briefly, CD133 ${ }^{+}$SMMC-7721 cells were seeded in six-well plates and grown overnight. Then the cells were transfected at a multiplicity of infection (MOI) of 50 with the miR-150 or miR-control, and $24 \mathrm{~h}$ later the medium was changed to fresh culture medium.

Flow cytometry analysis. The CD133 expression studies were carried out according to the instructions. Briefly, the fresh sorted cells were blocked in FcR Blocking Reagent Kit and labeled with FITC-conjugated anti-human CD133/2 (Miltenyi Biotec). Isotype-matched mouse antibodies served as controls. The flow
Table I. Characteristics of HCC patients analyzed in this study.

\begin{tabular}{lcccrc}
\hline $\begin{array}{l}\text { Serial } \\
\text { no. }\end{array}$ & Gender & $\begin{array}{c}\text { Age } \\
\text { (years) }\end{array}$ & $\begin{array}{c}\text { Cause of liver } \\
\text { disease }\end{array}$ & $\begin{array}{c}\text { AFP } \\
(\mathrm{ng} / \mathrm{ml})\end{array}$ & Grading \\
\hline 1 & $\mathrm{M}$ & 54 & HBV & 4055 & $\mathrm{G} 3$ \\
2 & $\mathrm{~F}$ & 33 & HBV & 58211 & $\mathrm{G} 2$ \\
3 & $\mathrm{M}$ & 56 & HBV & 4022 & $\mathrm{G} 3$ \\
4 & $\mathrm{M}$ & 58 & None & 27.14 & $\mathrm{G} 3$ \\
5 & $\mathrm{~F}$ & 39 & HBV & 83.42 & $\mathrm{G} 2$ \\
\hline
\end{tabular}

cytometry analysis of cell cycle and apoptosis were carried out using a FACSCalibur flow cytometer (BD Biosciences, USA). Annexin $\mathrm{V}$ and propidium iodide (PI) dual staining was used to visualize apoptotic cells.

Colony formation and tumorsphere formation assays. For colony formation assays, $1,000 \mathrm{CD} 133^{+}$or CD133- SMMC7721 cells were seeded in 6-cm culture plates (Cornig, USA). After 3 weeks, the colonies were stained with Giemsa solution. Tumorsphere formation assays were performed essentially as previously described (25). Briefly, single cell suspensions of $10,000 \mathrm{CD} 133^{+}$or CD133- SMMC-7721 cells were seeded in ultra-low 6-well plates (Cornnig, USA). Tumorspheres were observed after 7 days under inverted microscope (Olympus, Tokyo, Japan).

Xenograft tumorigenicity assay. Six- to eight-week-old NOD/ SCID mice were purchased from Chongqing University of Medical Sciences (Chongqing Province, China). The protocols were approved by the institutional Animal Care and Use Committee. All mice were randomly divided into groups (5 mice/ group) and maintained under standard conditions according to the institutional guidelines. For subcutaneous inoculation, various numbers of $\mathrm{CD}^{133^{+}}$or $\mathrm{CD}^{3} 33^{-}$cells ranging from 100 to 10,000 cells were suspended in DMEM/F12 and Matrigel (Invitrogen) mixture (1:1), and subcutaneous injection was performed. All animals were sacrificed with an overdose of ketanest and xylazine. The incidence of subcutaneous tumors was recorded. To examine the expression of CD133 in the transplanted cells, the grafts were treated with collagenase, and the isolated cells were analyzed by FACS. The subcutaneous tumors were formalinfixed and paraffin-embedded for histological analysis.

RNA extraction, real-time PCR and semi-quantitative RT-PCR. Total RNA was extracted from cells using TRIzol (Invitrogen, USA). Revere transcription was performed on $10 \mathrm{ng}$ of total RNA, cDNA was used in PCR reactions of 40 cycles $\left(94^{\circ} \mathrm{C}\right.$, $5 \mathrm{~min}, 94^{\circ} \mathrm{C} 30 \mathrm{sec}, 58^{\circ} \mathrm{C}, 30 \mathrm{sec}, 72^{\circ} \mathrm{C}, 40 \mathrm{sec}$ ). miRNA levels were determined by real-time PCR. Amplification and detection of specific products were performed with the Rotor-Gene 3000 real-time PCR system (Corbett Research). All the primers used for real-time PCR are listed in Table II. The target PCR Ct values were normalized by subtracting it by U6 Ct value. RT-PCR was performed under linear conditions in order to reflect the original amount of the specific transcriptions. The RT-PCR primers were as follows: c-Myb forward 5'-AGAGGGCAATGGGACTAA ACC-3', reverse 5'-CTACAGTCTCCAGTGGCTAAGG-3'; 
Table II. Reverse transcription and stem-loop primer for real-time PCR.

\begin{tabular}{|c|c|c|}
\hline Gene name & Reverse transcription primer $\left(5^{\prime}-3^{\prime}\right)$ & $\begin{array}{l}\text { PCR primer }\left(5^{\prime}-3^{\prime}\right) \\
\text { F: forward primer } \\
\text { R: reverse primer }\end{array}$ \\
\hline \multirow[t]{2}{*}{ hsa-miR-519e } & 5'GTCGTATCCAGTGCGTGTCGTGGAGTC & F: GGAAGTGCCTCCTTTTAG \\
\hline & GGCAATTGCACTGGATACGACAACACT3' & R: TGCGTGTCGTGGAGTC \\
\hline \multirow[t]{2}{*}{ has-miR-150 } & 5'GTCGTATCCAGTGCGTGTCGTGGAGTC & F: GCTCTCCCAACCCTTGT \\
\hline & GGCAATTGCACTGGATACGACCACTGGT3' & R: TGCGTGTCGTGGAGTC \\
\hline \multirow[t]{2}{*}{ hsa-miR-888 } & 5'GTCGTATCCAGTGCGTGTCGTGGAGTC & F: GGGGTACTCAAAAAGCTG \\
\hline & GGCAATTGCACTGGATACGACTGACTGA3' & R: TGCGTGTCGTGGAGTC \\
\hline \multirow[t]{2}{*}{ hsa-miR-152 } & 5'GTCGTATCCAGTGCGTGTCGTGGAGTC & F: GGAATCAGTGCATGACAGA \\
\hline & GGCAATTGCACTGGATACGACCCAAGT3' & R: CAGTGCGTGTCGTGGA \\
\hline \multirow[t]{2}{*}{ hsa-mir-532-5p } & 5'GTCGTATCCAGTGCGTGTCGTGGAGT & F: GCCCATGCCTTGAGTGTAG \\
\hline & CGGCAATTGCACTGGATACGACACGGTC3' & R: GTGCGTGTCGTGGAGTCG \\
\hline
\end{tabular}

$\beta$-actin forward 5'-AGCGAGCATCCCCCAAAGTT-3', reverse 5'-GGGCACGAAGGCTCATCATT -3'. $\beta$-actin was used as an internal control. PCR products were analyzed by $2.5 \%$ agarose gels.

Cell proliferation assays. Cell proliferation was examined on days $0,1,2,3,4$ and 5 after inoculation by means of a cell proliferation assay using Cell Counting Kit-8 (CCK-8) (Beyotime Ins. Biotec, China) according to the manufacturer's instructions. The optical density was measured using the microplate reader at a wavelength of $450 \mathrm{~nm}$.

Luciferase reporter assay. The 3'UTR fragment (nt904 to nt910 and nt968 to nt974) of human c-Myb mRNA contained 2 putative target sites for miR-150. The fragment was cloned into the firefly luciferase reporter vector pMIR-Report (Ambion). Mutation of the c-Myb 3'UTR at the miR-150 binding site was performed using the Quick change-mutagenesis kit (Stratagene, Heidelberg, Germany). For reporter assays, the cells were plated in 24-well plates, and co-transfected with wild-type or mutant reporter and miR-150-expression plasmid using Lipofectamine 2000 (Invitrogen). Cells were harvested $48 \mathrm{~h}$ after transfection and lysed in lysis buffer. Luciferase activity was measured using the dual luciferase reporter assay system (Promega).

Western blot analysis. Cell lysis, sample preparation, SDS-PAGE separation and electro-transferring to nitrocellulose membrane were performed with standard methods. The primary antibodies used for analysis included rabbit anti-cMyb polyclonal Ab (1:1000), rabbit anti-cyclin D1 polyclonal $\mathrm{Ab}$ (1:1000), mouse anti-Bcl-2 mAb (1:1000), mouse antiCD133 mAb (1:1000), and mouse anti- $\alpha$-tubulin mAb (1:1000), all from Santa Cruz Biotechnology (Santa Cruz, USA). The signal was visualized with ECL chemiluminescent substrates on X-ray film (Kodak, USA). The expression levels were quantified as the band density on X-film using Image Quant software, calculated as the ratio to $\alpha$-tubulin expressed in the same sample.

Statistical analysis. All values are presented as means \pm standard deviation (SD). Significant differences were determined using SPSS 11.5 software. Student's t-test analysis was used to determine the statistical difference. $\mathrm{P}<0.05$ was considered significant.

\section{Results}

Isolation of $\mathrm{CD} 133^{+}$and $\mathrm{CD} 133^{-}$fractions from primary $\mathrm{HCC}$ sample. We used the antibody coated magnetic beads (Miltenyi Biotec) to sorted cancer stem cells $\left(\mathrm{CD} 133^{+}\right)$and non-stem (CD133') cells from primary HCC samples derived from five patients. The $\mathrm{CD}_{133^{+}}$subpopulations in the freshly dissociated primary HCC cells ranging from 0.20 to $9.13 \%$ were analyzed by flow cytometry (Fig. 1A). After sorting, the content of $\mathrm{CD}_{133}{ }^{+}$subpopulation was enriched up to $99.73 \%$ (Fig. 1B) and each fraction formed tumorspheres within 24-72 h, whereas the CD133- cells did not exhibit tumorsphere formation (Fig. 1C).

Microarray analysis of miRNA expression profiling. To examine the differential expression profile of miRNAs in $\mathrm{CD}_{133^{+}}$and CD133- HCC fractions, miRNA microarray analysis was performed using the miRCURY LNAArray (v.14.0) from Exiqon. Heat map and hierachical clustering analysis are shown in Fig. 2A. The results show that cell samples were clustered according to expression profile of 1.5-fold differentially expressed miRNAs between $\mathrm{CD}_{133^{+}}$and $\mathrm{CD} 133^{-}$of primary $\mathrm{HCC}$ fractions. Interestingly, several miRNAs were up-regulated in the CD133 HCC fractions (Table II). These include hsa-miR-150, hsa-miR-152, hsa-miR-888, hsa-miR-519e, hsa-miR-532-5p.

To further confirm results from microarray and to examine tissue distribution of miRNA expression, 5 miRNAs from the 
A
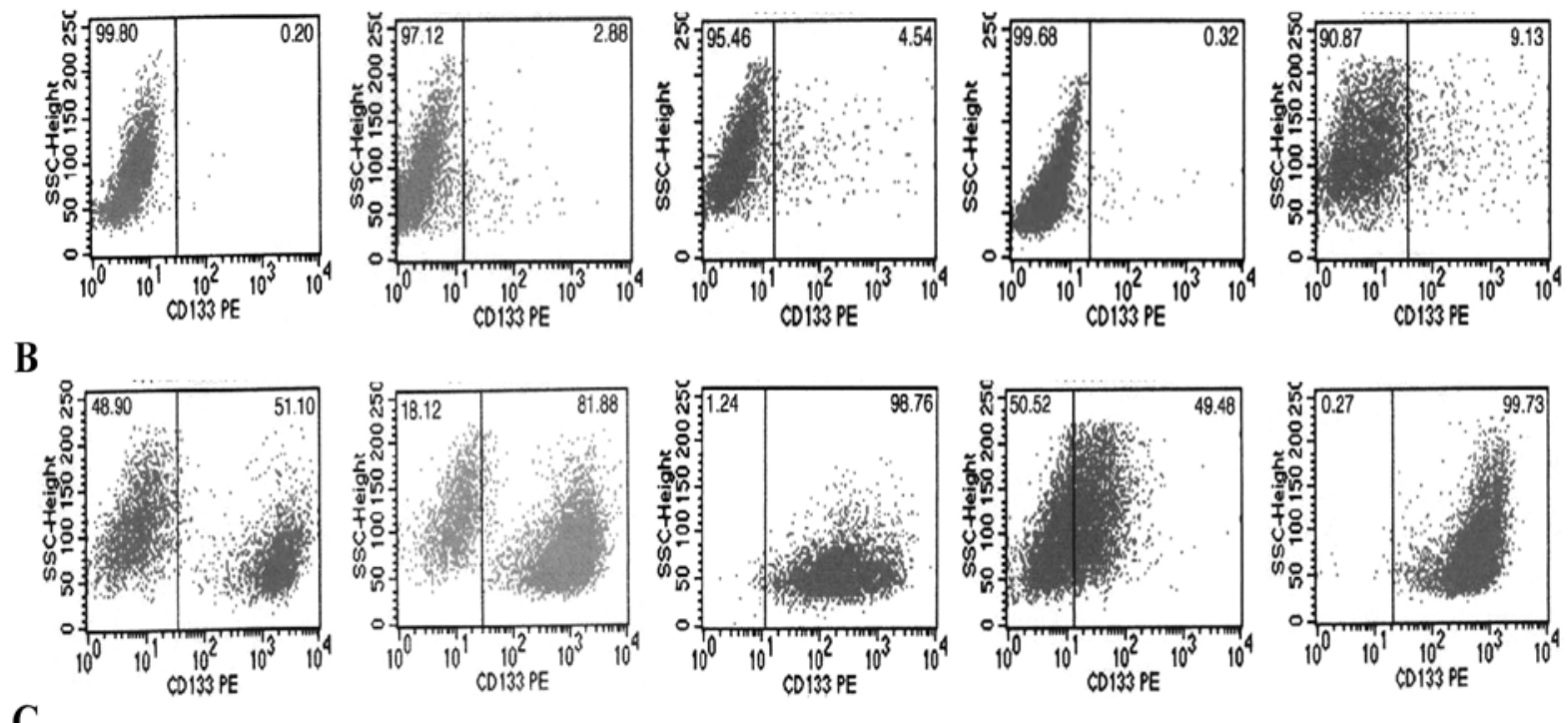

C

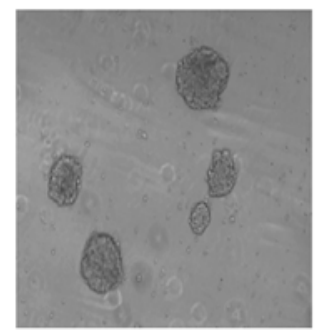

CD133+

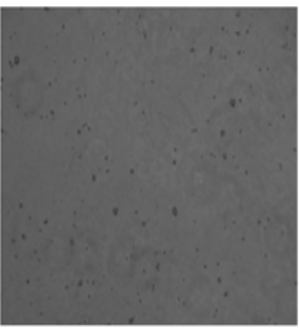

CD133-
Table III. The miRNAs with at least 1.5 -fold changes in CD133 vs. CD $133^{+}$HCC fractions.

\begin{tabular}{llc}
\hline microRNA & Genome location & Fold-change \\
\hline $\begin{array}{l}\text { Up-regulated } \\
\text { hsa-miR-519e }\end{array}$ & 19q13.42 & 2.39 \\
hsa-miR-150 & $19 \mathrm{q} 13.33$ & 1.54 \\
hsa-miR-888 & Xq27.3 & 2.00 \\
hsa-miR-152 & $17 \mathrm{q} 21.32$ & 3.04 \\
hsa-miR-532-5p & Xp11.23 & 2.85 \\
& & \\
Down-regulated & & \\
hsa-miR-802 & $21 \mathrm{q} 22.12$ & 0.19 \\
hsa-miR-1273 & $8 \mathrm{q} 22.2$ & 0.45 \\
hsa-miR-193b & $16 \mathrm{p} 13.12$ & 0.61 \\
hsa-miR-1248 & $3 \mathrm{q} 27.3$ & 0.26 \\
hsa-miR-184 & $15 \mathrm{q} 25.1$ & 0.27 \\
hsa-miR-224 & Xq28 & 0.45 \\
hsa-miR-920 & $12 \mathrm{p} 12.1$ & 0.47 \\
hsa-miR-630 & $15 \mathrm{q} 24.1$ & 0.48 \\
hsa-miR-636 & $17 \mathrm{q} 25.1$ & 0.33 \\
\hline
\end{tabular}

up-regulated ones were chosen for real-time PCR. Compared with $\mathrm{CD} 133^{+} \mathrm{HCC}$ fractions, the expression levels of hsa-miR-150,
Figure 1. Characterization of primary HCC by expression CD133. (A) The expression of CD133 in primary tumor cells, obtained from five HCC patients. The percentages of $\mathrm{CD}_{133}{ }^{+}$fractions ranged from 0.20 to $9.13 \%$ before sorting. (B) After sorted by MACS, the percentages of CD133+ fractions ranged from 49.48 to $99.73 \%$. (C) Tumorspheres were found in the $\mathrm{CD} 133^{+}$fractions of the primary HCC cells. The CD133- fractions did not form tumorspheres.

hsa-miR-152, hsa-miR-888, hsa-miR-519e, and hsa-miR-532-5p were higher in $\mathrm{CD}_{133^{-}} \mathrm{HCC}$ fractions (Fig. 2B).

Sorting of $\mathrm{CD} 133^{+}$cells from $\mathrm{HCC}$ cell line SMMC-7721. We examined a series of human HCC cell lines (SMMC-7721, Huh-7, and Hep3B) for miR-150 expression. SMMC-7721 cells have very low expression level of miR-150, but high levels of the miR-150 target gene c-Myb (not shown). Based on these data and our observation that they are reproducible from tumorspheres, we chose the SMMC-7721 cells for the current study. To define the frequency of $\mathrm{CD} 133^{+}$cells in SMMC-7721 cell line, we evaluated the CD133 expression by flow cytometry. As shown, we found that $\mathrm{CD} 133^{+}$cells were only a small fraction of in SMMC-7721 (0.15-0.54\%). We successfully enriched CD133+ and CD133 populations from SMMC-7721 cells by MACS, with $>98 \%$ purity in $\mathrm{CD}_{133^{+}}$cells after sorting (Fig. 3A). Differential expression level of CD133 protein in the sorted populations was confirmed by Western blotting. Notably, we found the expression of CD133 protein was significantly increased in the CD133+ cells (Fig. 3B). In addition, we observed a marked change in cellular morphology between $\mathrm{CD}^{-133^{+}}$and CD133- SMMC-7721 cells. The CD133- SMMC-7721 cells grew as evenly distributed adherent monolayers, whereas $\mathrm{CD} 133^{+}$SMMC-7721 cells grew in aggregate clusters of cells (Fig. 3C). To evaluate the self renewal potential of $\mathrm{CD}_{133^{+}}$SMMC-7721 cells, flow cytometry was performed to characterize the phenotype of $\mathrm{CD} 133^{+}$ SMMC-7721 cells that were culture for 7 days. FACS analysis revealed that the cultured cells consisted of $1.12 \% \mathrm{CD} 133^{+}$cells 
A

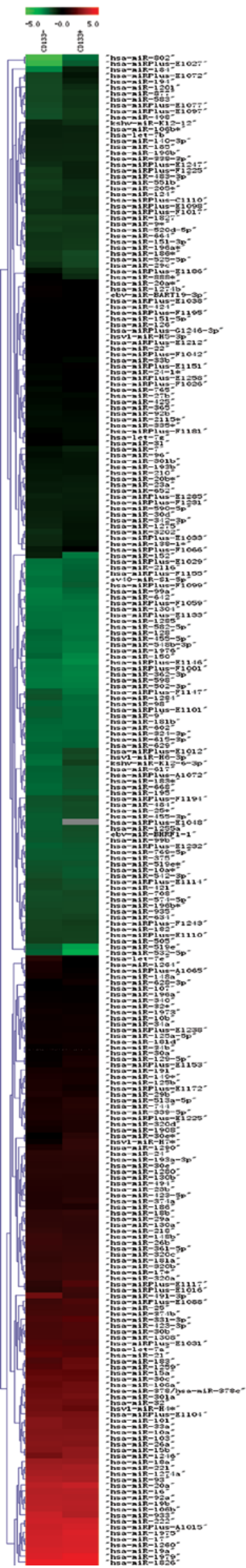

$\mathbf{B}$

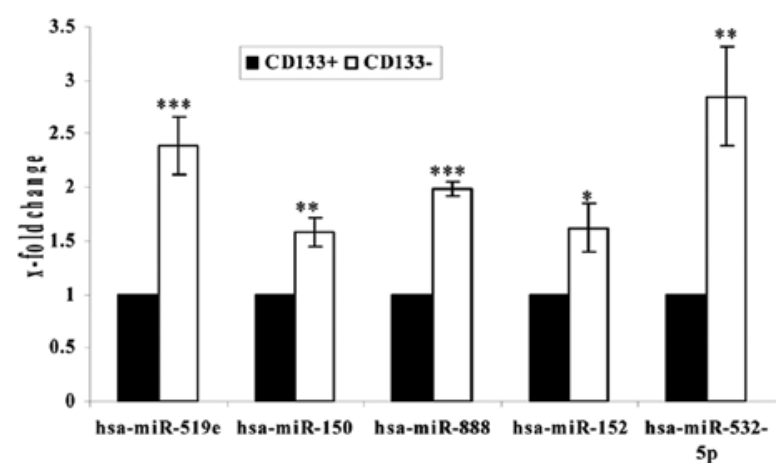

Figure 2. Expression of different miRNAs in primary $\mathrm{HCC} \mathrm{CD} 133^{+}$and CD133 fractions. (A) The heat map diagram shows the result of the two-way hierarchical clustering of genes and samples. The color scale illustrates the relative expression level of a miRNA: red color represents a high expression level; green color represents a low expression level. (B) Validation of microarray data using real-time PCR. The levels of miR-519e, miR-150, miR-888, miR-152 and miR-532-5p are significantly increased in the CD133 fractions compared to the $\mathrm{CD}_{133^{+}}$fractions. The target PCR Ct values were normalized by subtracting the U6 Ct value. Results are presented as the means $\pm \mathrm{SD}$ of three independent experiments. ${ }^{*} \mathrm{P}<0.05 ;{ }^{* *} \mathrm{P}<0.01 ;{ }^{* * *} \mathrm{P}<0.001$.

$\mathbf{A}$
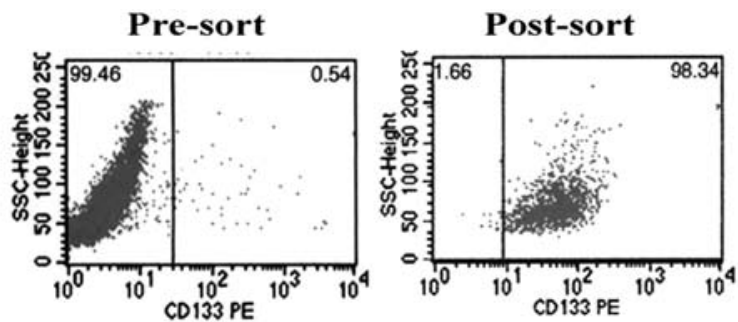

B

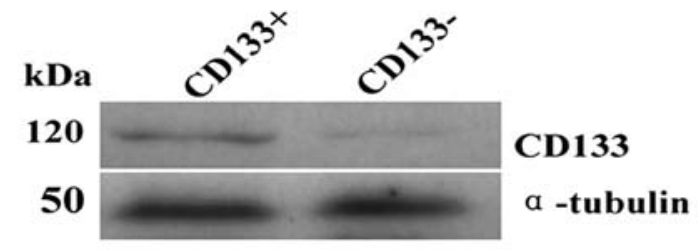

C

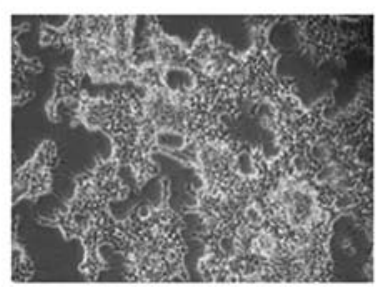

CD133+

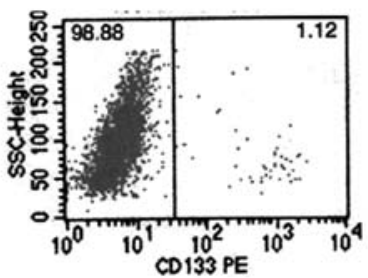

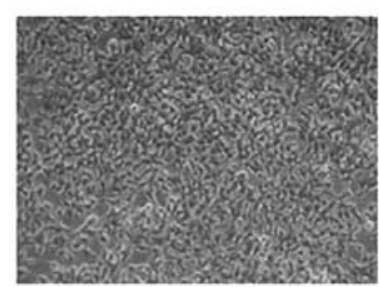

CD133-

Figure 3. The CD133 expression and sorting purity analysis in HCC cell lines. (A) Flow cytometry was used to analyze the expression of CD133 in SMMC7721 cells. The purity of MACS sorted $\mathrm{CD}_{133^{+}}$cells ranged from 81.88 to 98.34\% compared to unsorted SMMC-7721 cells (0.15-0.54\%). (B) Expression of CD133 in CD133 ${ }^{+}$and CD133- SMMC-7721 cells was examined by Western blot analysis. $\alpha$-tubulin was used as an internal control. (C) $\mathrm{CD} 133^{+}$and $\mathrm{CD} 133$ SMMC-7721 cells show different growth patterns. (D) CD133+ SMMC-7721 cells were cultured for 7 days. The expression levels of CD133 were examined by flow cytometry. 

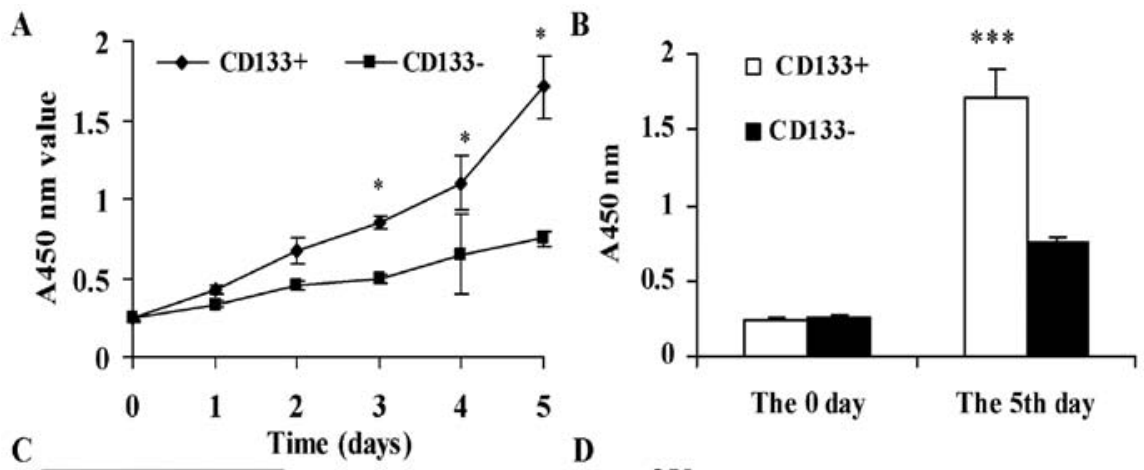

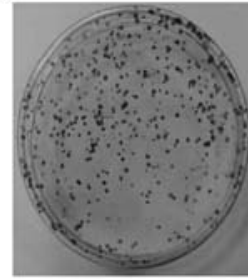

CD133+

E

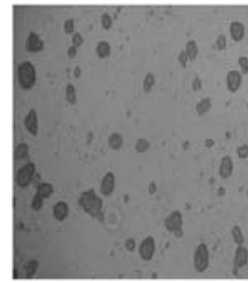

CD133+

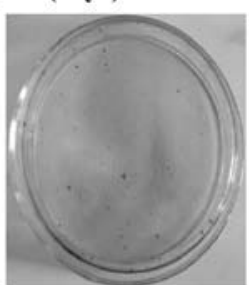

CD133-

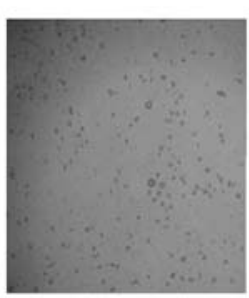

CD133-
D

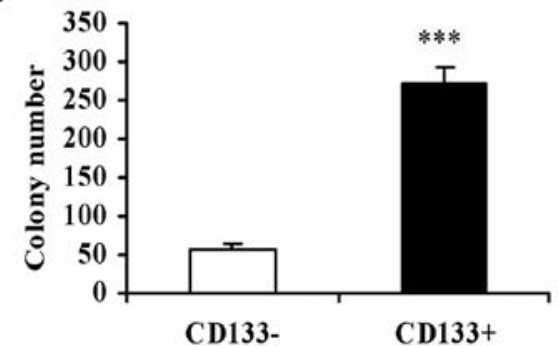

$\mathbf{F}$
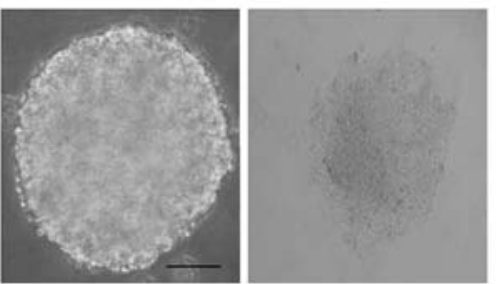

Figure 4. CD133+ SMMC-7721 cells possess higher cell proliferation, colony formation and tumorsphere formation ability. (A and B) Proliferation assays by CCK-8, showing that $\mathrm{CD} 133^{+}$cells (black rhombus) possess significantly higher proliferation than CD133- cells (black squares). (C) Representative photographs of the plates containing colonies derived from $\mathrm{CD}^{3} 33^{+}$or $\mathrm{CD} 133^{-}$cells. (D) The results at 3 weeks for colony formation assays after plating are presented in the histogram. (E) Spheroids were found in the $\mathrm{CD}_{133^{+}}$cells, whereas the $\mathrm{CD} 133^{-}$cells did not form spheroids (original magnification x100). (F) A representative phase contrast image of $\mathrm{CD}_{133^{+}}$cell spheroids is shown (scale bar $50 \mu \mathrm{m}$ ). Spheroids formed from $\mathrm{CD}_{133^{+}}$cells were removed from the serum-free medium and allowed to attach to the substratum. Expanding adherent cells from the spheroids can be observed at two days of culture (original magnification $\mathrm{x} 400$ ). Data represent the means $\pm \mathrm{SD}$ derived from triplicate samples. ${ }^{* * * *} \mathrm{P}<0.001$.

and $98.88 \%$ CD133 cells (Fig. 3D). This proportion was consistent with the initial composition of SMMC-7721 cells.

CD133+ $\mathrm{HCC}$ cells show higher proliferation, colony formation, and tumorsphere formation ability. To determine whether $\mathrm{CD} 133^{+}$cells represent the CSCs phenotype, we carried out the cell proliferation, colony formation and spheroid formation ability assays. As shown in Fig. 4A and B, CD133+ cells possessed significantly higher proliferation than $\mathrm{CD} 133^{-}$cells. The proliferation rate of $\mathrm{CD} 133^{+}$cells was significantly higher than CD133- cells on the fifth day. In the colony formation assay, we found $\mathrm{CD} 133^{+}$cells possessed higher colony formation efficiency than CD133 cells. As shown in Fig. 4C and D, $\mathrm{CD}_{133^{+}}$cells formed larger and greater number of colonies than CD133- cells. We further pursued these cells for their ability to form tumorspheres as an indicator of stem cell self-renewal. We found that the $\mathrm{CD} 133^{+}$cells formed tumorspheres within $48 \mathrm{~h}$, whereas the CD133- cells did not form tumorspheres (Fig. 4E). Furthermore, CD133+ cells formed tumorspheres efficiently, reaching $\sim 200 \mu \mathrm{m}$ in diameter after 7 days of culture (Fig. 4F).

Tumor formation and self-renewal of $\mathrm{CD} 133^{+}$cells. To determine whether $\mathrm{CD} 133^{+}$cells were capable of tumor initiation,
Table IV. Tumor-initiation study.

\begin{tabular}{ccc}
\hline $\begin{array}{l}\text { Cell no. injected } \\
\text { per mice }\end{array}$ & $\begin{array}{c}\mathrm{CD} 133^{+} \mathrm{HCC} \\
\text { cells }\end{array}$ & $\begin{array}{c}\mathrm{CD} 133^{-\mathrm{HCC}} \\
\text { cells }\end{array}$ \\
\hline 100 & $0 / 5^{\mathrm{a}}$ & $0 / 5$ \\
1,000 & $2 / 5$ & $0 / 5$ \\
10,000 & $5 / 5$ & $0 / 5$ \\
\hline
\end{tabular}

$\mathrm{CD}_{133^{+}}$and CD133- cells subcutaneously inoculated into two opposite sites of the same recipient NOD/SCID mouse. Tumor formation was observed for 6 weeks after inoculation. ${ }^{a}$ Data are number of mice with tumors formed/number of mice inoculated.

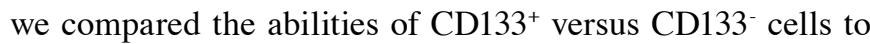
initiate tumor formation in NOD/SCID mice. An apparent difference in tumorigenicity was observed between $\mathrm{CD}_{133^{+}}$and CD133 cells (Table IV). As few as $1,000 \mathrm{CD}^{-} 33^{+}$cells were sufficient to initiate tumors in 2 of 5 subcutaneous inoculations in NOD/SCID mice 6 weeks after inoculation. Furthermore, $10,000 \mathrm{CD} 133^{+}$cells produced tumors in 5 of 5 inoculations in NOD/SCID mice, whereas no tumors were found in inocula- 
A

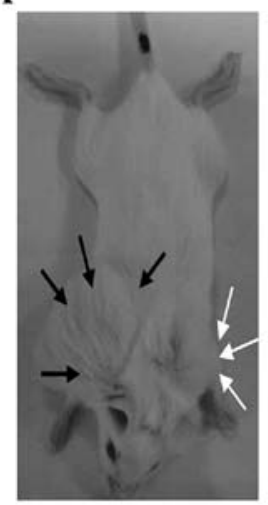

B

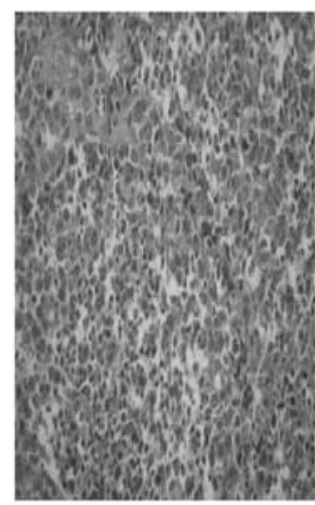

C

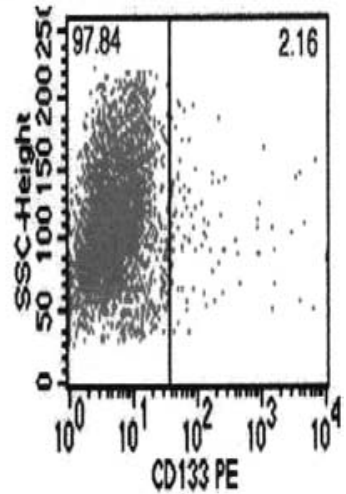

Figure 5. Tumorigenic potential of CD133+ SMMC-7721 cells. (A) Representative examples of NOD/SCID mice injected subcutaneously with CD133+ and CD133 cells freshly isolated from SMMC-7721 cells. Tumor nodules, indicated by black arrows, were only observed in mice injected with CD133 ${ }^{+}$cells. Injection site of CD133- cells, indicated by white arrows, revealed no tumor. (B) H\&E staining of a subcutaneous tumor revealed that the histological feature of a xenograft tumor induced by $\mathrm{CD}_{133^{+}}$cells (original magnification $\mathrm{x} 400$ ). (C) The subcutaneous tumor was applied with collagenase and the expression of CD133 of the isolated cells were examined by flow cytometry.

\section{A}

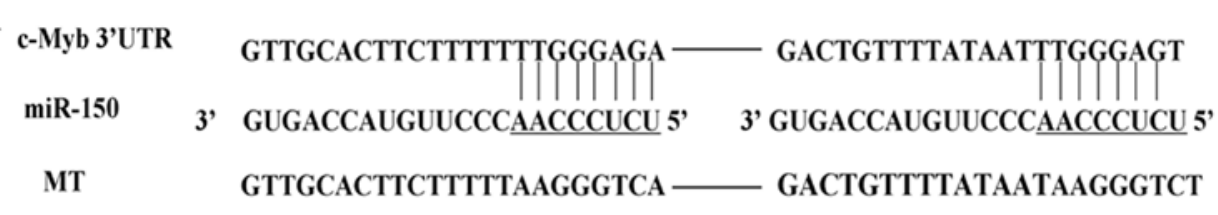

$\operatorname{miR}-150$

3' GUGACCAUGUUCCCAACCCUCU 5',

3' GUGACCAUGUUCCCAACCCUCU 5,

B

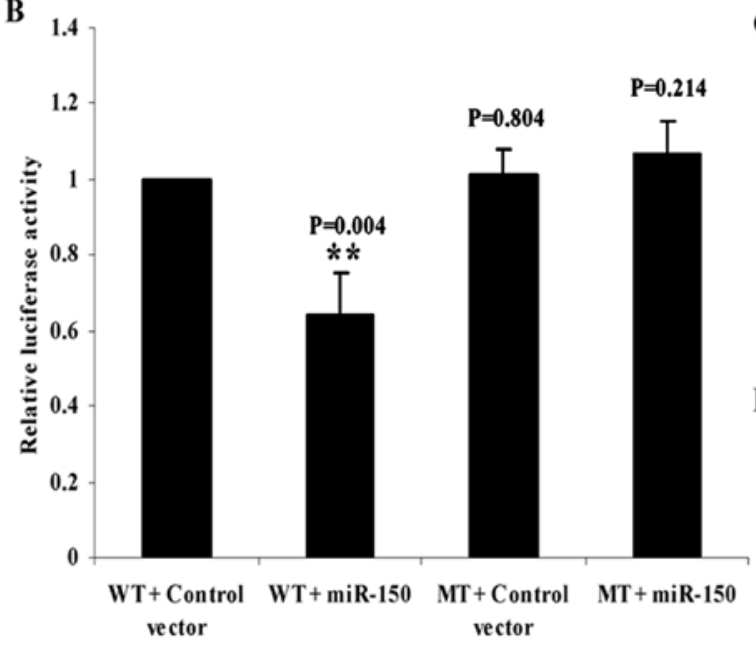

C

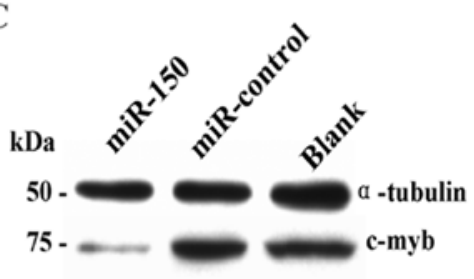

D

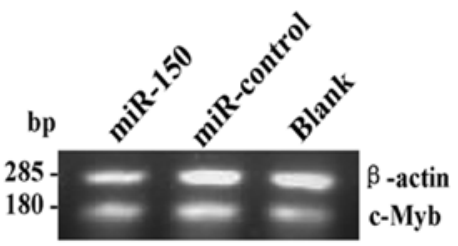

Figure 6. c-Myb 3'UTR is a target of miR-150. (A) Two miR-150 potential target sites reside at nucleotides 904-910 and nucleotides 968-974 of the c-Myb 3'UTR. c-Myb 3'UTR MT contained mutations of both predicted target sites to mismatch the seed region of miR-150. (B) Luciferase activity assay demonstrates a direct targeting of the 3'UTR of c-Myb by miR-150. (C) Detection of c-Myb protein expression levels by Western blot analysis. $\alpha$-tubulin was used as an internal control. (D) The c-Myb mRNA expression levels were determined by semi-quantitative RT-PCR. The relative expression ratio of c-Myb mRNA and protein is shown as the means $\pm \mathrm{SD}$. ${ }^{*} \mathrm{P}<0.05$.

tion of 10,000 CD133- cells (Fig. 5A). Hematoxylin-eosin (H\&E) staining analysis of xenograft tumors showed a highly cellular mass below the $\mathrm{CD} 133^{+}$cell injection site (Fig. 5B). To determine whether $\mathrm{CD} 133^{+}$cells self-renew and generate CD133- cells in vivo, flow cytometry analysis was performed to characterize the $\mathrm{CD}_{133^{+}}$engraftment (Fig. 5C). FACS analysis revealed that the tumor cells consisted of $2.16 \% \mathrm{CD}^{2} 33^{+}$cells and $97.84 \%$ CD133 cells.

The c-Myb is a direct target of miR-150. To gain insights into the biological functions of miR-150, we performed analysis of potential targets of miR-150 using two common prediction algorithms, TargetSCAN (http://www.targetscan.org/) and PicTar (http://pictar.mdc-berlin.de/) focusing on genes known to regulate cell proliferation, differentiation and survival. c-Myb was among the top target genes predicted for miR-150.

To determine whether c-Myb is a direct target of miR-150, we integrated a fragment of the c-Myb-3'UTR containing the target sequence, or a fragment of the c-Myb-3'UTR-mut, into a luciferase reporter vector (Fig. 6A). Cotransfection with c-Myb3'UTR and miR-150 caused a $36 \%$ decrease in the luciferase activity compared with the negative control (Fig. 6B). These 
$\mathbf{A}$

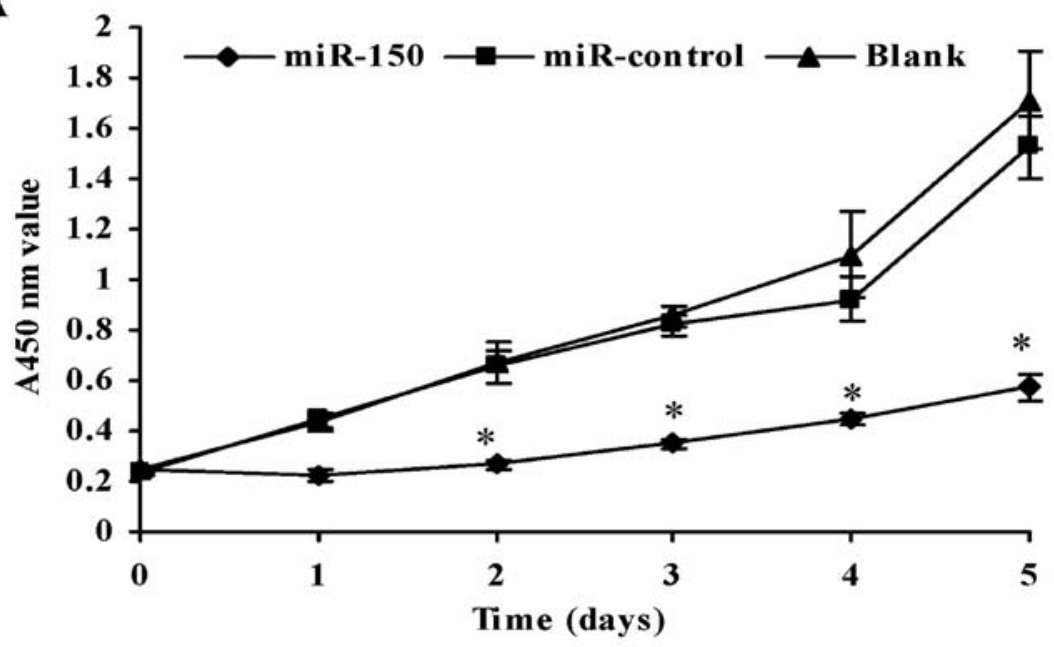

B
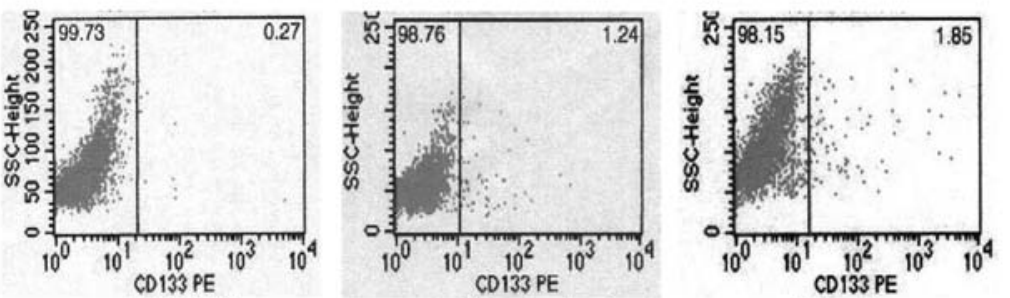

C

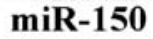

miR-control

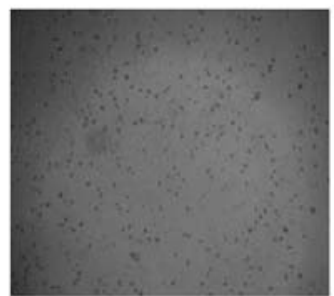

$\operatorname{miR-150}$

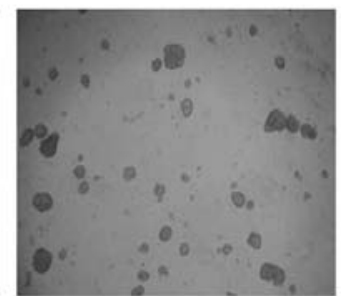

miR-control

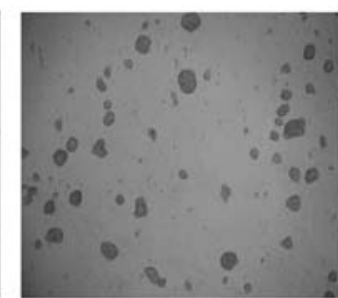

Blank

Figure 7. Function of miR-150 on proliferation and tumorsphere formation. (A) Proliferation curves of CD133+ cells transfected with miR-150 (black rhombus) or miR-control (black squares) compared to the blank control (black triangle). Cell number was determined at $450 \mathrm{~nm}$ at the indicated time. (B) Overexpression of miR-150 significantly reduced the CD133+ cells. (C) Overexpression of miR-150 showed a partial dispersion of tumorspheres and reduction tumorsphere size. Data represent the means $\pm \mathrm{SD}$ derived from three determinations. ${ }^{*} \mathrm{P}<0.05$.

results suggested that $3^{\prime} \mathrm{UTR}$ of human c-Myb gene contains target sites specific for miR-150. Western blot analysis was performed to determine the effect of overexpression of miR-150 on c-myb protein expression. The results demonstrated that overexpression of miR-150 in $\mathrm{CD}_{133^{+}}$cells significantly decreased c-Myb protein expression, while the miR-control or blank control had no effect on expression of c-Myb protein (Fig. 6C). RT-PCR analysis demonstrated that miR-150 has little if any effect on c-Myb mRNA levels (Fig. 6D).

Overexpression of miR-150 leads to a significant reduction of $\mathrm{CD}_{133^{+}}$cells and inhibition of tumorsphere growth. To investigate the potential role of miR-150 in liver cancer stem cells, we examined whether overexpression of miR-150 could inhibit the $\mathrm{CD}_{133^{+}}$cells and their self-renewal potential. Fig. 7A shows that $\mathrm{CD}_{133^{+}}$cells transfected with miR-150 displayed a significantly reduced proliferation rate, compared to cells transfected with miR-control. Our results demonstrate that overexpression of miR-150 significantly decreased the CD133 ${ }^{+}$ cells $(0.38 \pm 0.09 \%$ versus miR-control $1.95 \pm 0.18 \%, \mathrm{P}=0.013$, $\mathrm{n}=2$ ), and $80 \%$ reduction (Fig. $7 \mathrm{~B}$ ). This miR-150-induced reduction of the $\mathrm{CD}_{133^{+}}$cells was accompanied by reduced tumorsphere formation and smaller size of the tumorspheres (Fig. 7C).

Overexpression of miR-150 leads to cell cycle arrest and promotes apoptosis in $\mathrm{CD}_{133^{+}}$cells. Overexpression of miR-150 inhibits $\mathrm{CD}_{133^{+}}$cells proliferation and leads to partial dispersion of spheroids. Thus, we looked for potential cell cycle and apoptosis alterations in $\mathrm{CD}_{133^{+}}$cells transfected with miR-150. FACS showed that overexpression of miR-150 induced a $42 \%$ decrease in S-phase fractions, and an increase in $\mathrm{G}_{1}$ of $33 \%$, as compared to the cells transfected with miR-control (Fig. 8A and B). Furthermore, we also measured the apoptotic cells by flow cytometry analysis. It was observed that up to $25.21 \pm 9.26 \%$ of $\mathrm{CD}_{133^{+}}$cells became apoptotic on $72 \mathrm{~h}$ after transfected with miR-150, whereas the apoptosis was $6.39 \pm 1.02 \%$ in the blank control group (Fig. 8C and D). We additionally examined expression of several molecules involved in cell cycle and cell survival regulation. As illustrated in Fig. 7E, overexpression of miR-150 significantly decreased the expression of cyclin D1 and Bcl-2 protein levels. 
A

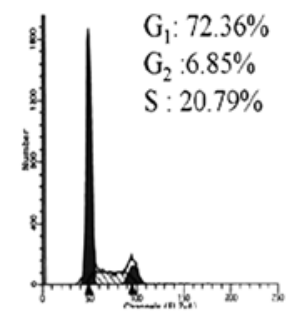

$\operatorname{miR}-150$

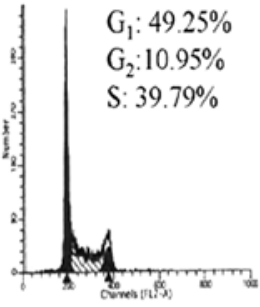

miR-control

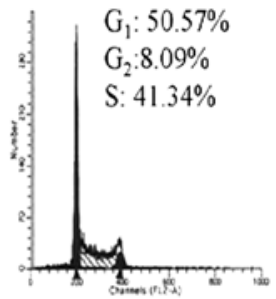

Blank
B

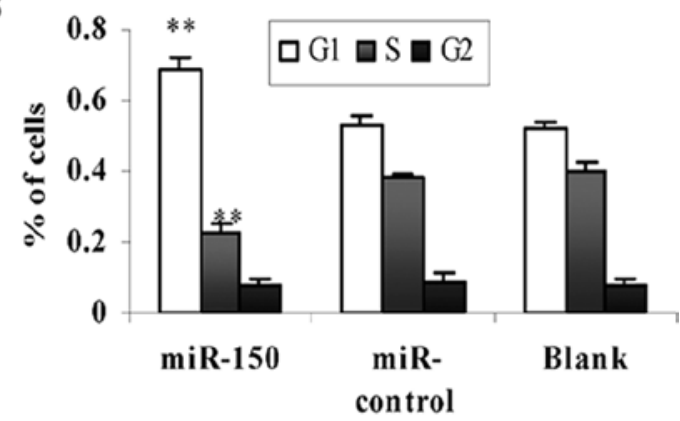

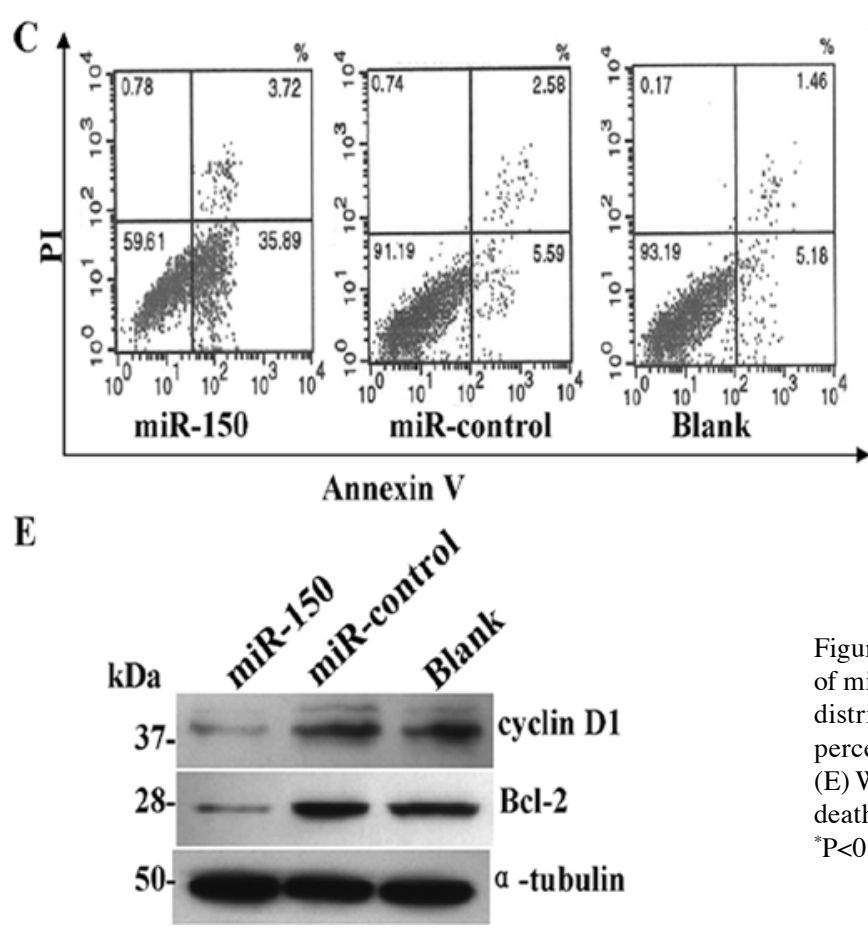

$\mathrm{C}$

E

\section{Discussion}

This study is based on the cancer stem cells (CSCs) hypothesis that tumors contain only a small subset of cells which maintain the proliferation, self-renewal and differentiation of tumor. Therefore, according to CSCs model $(26,27)$, targeting the minor population of CSCs may be a effective and curative therapeutic strategy for eradicating cancer. Here, we sorted $\mathrm{CD} 133^{+}$cells from SMMC-7721 cells, which demonstrated many CSCs-like properties. We used $\mathrm{CD}_{133^{+}}$liver CSCs as a model for testing the differences in expression profiles of miRNAs since recent studies suggest a role for miRNAs in CSCs (28-32).

Our analysis of differential expression of miRNAs in $\mathrm{CD}_{133^{+}}$and $\mathrm{CD} 133^{-}$of primary $\mathrm{HCC}$ tumor fractions revealed overexpression of several miRNAs in the CD133- fractions. Among the differentially expressed miRNAs, we focused on the hsa-miR-150, as miR-150 was recently reported selectively expressed in hematopoietic progenitors and certain solid tumors (34-37). However, the biological functions and mechanisms of miRNA-150 in liver CSCs have not been elucidated. It has become clear that the physiological function of miRNA is based on the regulation of only few critical target gene expressions in cellular context. In order to understand the impact and the molecular mechanisms underlying its function, we search for
Figure 8. Impact of miR-150 on cell cycle and apoptosis. (A and B) The effect of miR-150 on cell cycle was examined by flow cytometry analysis. Cell cycle distribution of CD133 ${ }^{+} \mathrm{HCC}$ cells transfected with miR-150. (C and D) The percentages of the Annexin V-positive early apoptotic cells are presented. (E) Western blot analysis on molecules that are regulators of cell cycle and cell death. Data represent the means \pm SD from three independent experiments. ${ }^{*} \mathrm{P}<0.05 ;{ }^{* *} \mathrm{P}<0.01$ target genes that may be regulated by miRNA-150. We explored the molecular mechanism underlying its function that c-Myb was a direct target of miR-150. c-Myb is a transcription factor that is involved in cell proliferation, differentiation, and survival (38-40).

In the present study, we overexpressed miR-150 in CD133+ cells and observed the effect on cell proliferation and tumorsphere formation. Surprisingly, overexpression of miR-150 significantly inhibited cell proliferation and led to partial dispersion of tumorspheres in CD133+ HCC cells. We next determined whether the effect of miR-150 on cell proliferation was related to cell cycle arrest and cell apoptosis. Overexpression of miR-150 increased the apoptosis and $\mathrm{G}_{1}$ arrest in the cell cycle of $\mathrm{CD}_{133^{+}} \mathrm{HCC}$ cells. This study demonstrated that overexpression of miR-150 in $\mathrm{CD} 133^{+} \mathrm{HCC}$ cells leads to alterations of several key proteins involved with cell cycle and cell survival, including cyclin D1 and Bcl-2. These changes can be attributed to the down-regulation of $\mathrm{c}-\mathrm{Myb}$ in response to miR-150 overexpression. The functional effects of c-Myb are modulated by transcription factors/cell cycle protein, including c-Myc, cyclinD1, Bcl-2 and Bcl-X (41-46).

In conclusion, our study demonstrated that miR-150 may be involved in $\mathrm{CD}_{133^{+}}$liver CSCs self-renewal, at least in part, through the direct negative regulation of the downstream target c-Myb. Overexpression of miR-150 led to increased percentage 
of cells in $\mathrm{G}_{1}$ phase and a substantial increase in cell apoptosis in $\mathrm{CD}_{133^{+}} \mathrm{HCC}$ cells. We observed down-regulation of cell cycle regulator cyclin D1 and cell survival regulator Bcl-2, which is generally consistent with the outcome of cell cycle arrest and cell apoptosis. Our study suggests that miR-150 may play a critical role in $\mathrm{CD}_{133^{+}}$liver CSC self-renewal and cell fate determination, and its potential function in liver CSCs may provide a novel therapeutic approach for HCC.

\section{Acknowledgements}

This work was supported by Grant 30970843 from the National Natural Science Foundation of China. We thank Shanghaikangchen Biotechnology company for providing with technical assistance with microarrays.

\section{References}

1. Reya T, Morrison SJ, Clarke MF and Weisman IL: Stem cell, cancer, cancer stem cells. Nature 414: 105-111, 2001.

2. Lapidot T, Sirard C, Vormoor J, et al: A cell initiating human acute myeloid leukaemia after transplantation into SCID mice. Nature 367: 645-648, 1994.

3. Singh SK, Hawkins C, Clarke ID, et al: Identification of human brain tumour initiating cells. Nature 432: 396-401, 2004.

4. Marsden CG, Wright MJ, Pochampally R and Rowan BG: Breast tumor-initiating cells isolated from patient core biopsies for study of hormone action. Methods Mol Biol 590: 363-375, 2009.

5. Wang L, Paul P and Lin CY: Characterization of stem cell attributes in human osteosarcoma cell lines. Cancer Biol Ther 8 : 543-552, 2009.

6. Ma S, Chan KW, Hu L, et al: Identification and characterization of tumorigenic liver cancer stem/progenitor cells. Gastroenterology 132: 2542-2556, 2007.

7. Dalerba P, Dylla SJ, Park IK, et al: Phenotypic characterization of human colorectal cancer stem cells. Proc Natl Acad Sci USA 104: 10158-10163, 2007.

8. Suetsugu A, Nagaki M, Aoki H, Motohashi T, Kunisada T and Moriwaki H: Characterization of $\mathrm{CD} 133^{+}$hepatocellular carcinoma cells as cancer stem/progenitor cells. Biochem Biophys Res Commun 351: 820-824, 2006

9. Yin S, Li J, Hu C, et al: CD133 positive hepatocellular carcinoma cells possess high capacity for tumorigenicity. Int J Cancer 120: 1444-1450, 2007.

10. Lee RC,Feinbaum RL and Ambros V: The C. elegans heterochronic gene lin-4 encodes small RNAs with antisense complementarity to lin-14. Cell 75: 843-854, 1993.

11. Reinhart BJ, Slack FJ, Basson M, et al: The 21-nucleotide let-7 RNA regulates developmental timing in Caenorhabditis elegans Nature 403: 901-906, 2000.

12. Bartel DP: MicroRNAs: genomics, biogenesis, mechanism, and function. Cell 116: 281-297, 2004.

13. Ambros V: The functions of animal microRNAs. Nature 431: 350-355, 2004

14. Zamore PD and Haley B: Ribo-gnome: the big world of small RNAs. Science 309: 1519-1524, 2005.

15. Garzon R, Fabbri M, Cimmino A, Calin GA and Croce CM MicroRNA expression and function in cancer. Trends Mol Med 12: 580-587, 2006.

16. Esquela-Kerscher A and Slack FJ: Oncomirs-microRNAs with a role in cancer. Nat Rev Cancer 6: 259-269, 2006.

17. Rosenfeld N, Aharonov R, Meiri E, et al: MicroRNAs accurately identify cancer tissue origin. Nat Biotechnol 26: 462-469, 2008.

18. Bandres E, Agirre X, Ramirez N, Zarate R and Garcia-Foncillas J: MicroRNAs as cancer players: potential clinical and biological effects. DNA Cell Biol 26: 273-282, 2007.

19. Deng S, Calin GA, Croce CM, Coukos G and Zhang L: Mechanisms of microRNA deregulation in human cancer. Cell Cycle 7: 2643-2646, 2008.

20. Tiscornia G and Izpisúa Belmonte JC: MicroRNAs in embryonic stem cell function and fate. Genes Dev 24: 2732-2741, 2010.

21. Wilson KD, Venkatasubrahmanyam S, Jia F, Sun N, Butte AJ and Wu JC: MicroRNA profiling of human-induced pluripotent stem cells. Stem Cells Dev 18: 749-758 2009.
22. Greco SJ and Rameshwar P: MicroRNAs regulate synthesis of the neurotransmitter substance $P$ in human mesenchymal stem cellderived neuronal cells. Proc Natl Acad Sci USA 104: 15484-15489, 2007.

23. Xiao C, Calado DP, Galler G, et al: MiR-150 controls B cell differentiation by targeting the transcription factor c-Myb. Cell 131: 146-159, 2007.

24. Cheng AM, Byrom MW, Shelton J and Ford LP: Antisense inhibition of human miRNAs and indications for an involvement of miRNA in cell growth and apoptosis. Nucleic Acids Res 33: 1290-1297, 2005.

25. Gibbs CP, Kukekov VG, Reith JD, et al: Stem-like cells in bone sarcomas: implications for tumorigenesis. Neoplasia 7: 967-976, 2005.

26. Korkaya $\mathrm{H}$ and Wicha MS: Selective targeting of cancer stem cells: a new concept in cancer therapeutics. Biodrugs 21: 299-310, 2007.

27. Winquist RJ, Boucher DM, Wood M and Furey BF: Targeting cancer stem cells for more effective therapies: Taking out cancer's locomotive engine. Biochem Pharmacol 78: 326-334, 2009.

28. Giuffrida D and Rogers IM: Targeting cancer stem cell lines as a new treatment of human cancer. Recent Pat Anticancer Drug Discov 5: 205-218, 2010.

29. Hatfield $\mathrm{S}$ and Ruohola-Baker $\mathrm{H}$ : microRNA and stem cell function. Cell Tissue Res 331: 57-66, 2008.

30. Mani SA, Guo W, Liao MJ, et al: The epithelial-mesenchymal transition generates cells with properties of stem cells. Cell 133: 704-715, 2008.

31. Marson A, Levine SS, Cole MF, et al: Connecting microRNA genes to the core transcriptional regulatory circuitry of embryonic stem cells. Cell 134: 521-533 2008.

32. Melton C, Judson RL and Bllelloch R: Opposing microRNA families regulate self-renewal in mouse embryonic stem cells. Nature 463: 621-626, 2010.

33. Monticelli S, Ansel KM, Xiao C, et al: MicroRNA profiling of the murine hematopoietic system. Genome Biol 6: R71, 2005.

34. Zhou B, Wang S, Mayr C, Bartel DP and Lodish HF: miR-150, a microRNA expressed in mature B and T cells, blocks early B cell development when expressed prematurely. Proc Natl Acad Sci USA 104: 7080-7085, 2007.

35. Zhou L, Qi X, Potashkin JA, Abdul-Karim FW and Gorodeski GI: MicroRNAs miR-186 and miR-150 down-regulate expression of the pro-apoptotic purinergic $\mathrm{P} 2 \mathrm{X} 7$ receptor by activation of instability sites at the 3'-untranslated region of the gene that decrease steady-state levels of the transcript. J Biol Chem 283: 28274-28286, 2008.

36. Wu Q, Jin H, Yang Z, et al: MiR-150 promotes gastric cancer proliferation by negatively regulating the pro-apoptotic gene EGR2. Biochem Biophys Res Commun 392: 340-345, 2010.

37. Lin YC, Kuo MW, Yu J, Kuo HH, Lin RJ, Lo WL and Yu AL: c-Myb is an evolutionary conserved miR-150 target and miR$150 / \mathrm{c}-$ Myb interaction is important for embryonic development. Mol Biol Evol 25: 2189-2198, 2008.

38. Mavilio F, Sposi NM, Petrini M, et al: Expression of cellular oncogenes in primary cells from human acute leukemias. Proc Natl Acad Sci USA 83: 4394-4398, 1986.

39. Slamon DJ, Boone TC, Murdock DC, Keith DE, Press MF, Larson RA and Souza LM: Studies of the human c-myb gene and its product in human acute leukemias. Science 233: 347-351, 1986.

40. Torelli G, Venturelli D, Coló A, et al: Expression of c-myb protooncogene and other cell cycle-related genes in normal and neoplastic human colonic mucosa. Cancer Res 47: 5266-5269, 1987.

41. Biroccio A, Benassi B, D'Agnano I, et al: c-Myb and Bcl-x overexpression predicts poor prognosis in colorectal cancer: clinical and experimental findings. Am J Pathol 158: 1289-1299, 2001.

42. Guérin M, Sheng ZM, Andrieu N and Riou G: Strong association between c-myb and oestrogen-receptor expression in human breast cancer. Oncogene 5: 131-135, 1990.

43. Weston K: Reassessing the role of C-MYB in tumorigenesis. Oncogene 18: 3034-3038, 1999.

44. Thorner AR, Parker JS, Hoadley KA and Perou CM: Potential tumor suppressor role for the c-Myb oncogene in luminal breast cancer. PLoS One 5: e13073, 2010.

45. Lei W, Liu F and Ness SA: Positive and negative regulation of c-Myb by cyclin D1, cyclin-dependent kinases, and p27 Kip1. Blood 105: 3855-3861, 2005.

46. Greco C, Alvino S, Buglioni S, et al: Activation of c-MYC and c-MYB proto-oncogenes is associated with decreased apoptosis in tumor colon progression. Anticancer Res 21: 3185-3192, 2001. 